\title{
Data mining of mental health issues of non-bone marrow donor siblings
}

\author{
Morihito Takita ${ }^{1 *}$, Yuji Tanaka', Yuko Kodama', Naoko Murashige', Nobuyo Hatanaka', Yukiko Kishi', \\ Tomoko Matsumura', Yukio Ohsawa ${ }^{2}$ and Masahiro Kami ${ }^{1}$
}

\begin{abstract}
Background: Allogenic hematopoietic stem cell transplantation is a curative treatment for patients with advanced hematologic malignancies. However, the long-term mental health issues of siblings who were not selected as donors (non-donor siblings, NDS) in the transplantation have not been well assessed. Data mining is useful in discovering new findings from a large, multidisciplinary data set and the Scenario Map analysis is a novel approach which allows extracting keywords linking different conditions/events from text data of interviews even when the keywords appeared infrequently. The aim of this study is to assess mental health issues on NDSs and to find helpful keywords for the clinical follow-up using a Scenario Map analysis.

Findings: A 47-year-old woman whose younger sister had undergone allogenic hematopoietic stem cell transplantation 20 years earlier was interviewed as a NDS. The text data from the interview transcriptions was analyzed using Scenario Mapping. Four clusters of words and six keywords were identified. Upon review of the word clusters and keywords, both the subject and researchers noticed that the subject has had mental health issues since the disease onset to date with being a NDS. The issues have been alleviated by her family.
\end{abstract}

Conclusions: This single subject study suggested the advantages of data mining in clinical follow-up for mental health issues of patients and/or their families.

Keywords: hematology, transplantation, data mining, Scenario Map analysis, physician-patient communication

\section{Introduction}

Allogeneic hematopoietic stem cell transplantation (alloHSCT) has been established as a treatment for hematologic malignancies such as leukemia and malignant lymphoma and is the only way to cure patients with advanced stage hematologic malignancies [1,2]. In Japan, allo-HSCTs were conducted on 2,242 cases in 2008 with a total of $33 \%$ of donors for the allo-HSCTs being siblings or relatives [3]. Several reports demonstrated that donating bone marrow or hematopoietic stem cells in peripheral blood can affect the donor's safety and quality of life, thus the donor's safety and quality of life should be carefully considered during allo-HSCT [4,5].

Undergoing allo-HSCT also increases the likelihood of patients and their families developing mental health

\footnotetext{
* Correspondence: takita-ygc@umin.net

'Division of Social Communication System for Advanced Clinical Research, the Institute of Medical Science, the University of Tokyo, 4-6-1 Shirokanedai, Minato-ku, Tokyo 108-8639, Japan

Full list of author information is available at the end of the article
}

issues [6-10]. Donor selection from relatives can occasionally cause psychological conflicts between a donor and other relatives, including non-donor siblings (NDS), which would result in difficult management for continuous medical follow-up. This is a practical concern but has not been well studied in previous reports $[11,12]$.

Data mining allows processing a large, multidisciplinary data set. Its effective applications into medical fields are highly desired since health care information has been dramatically increased and diversified $[13,14]$. Currently, the data mining approach has been applied to several clinical and biomedical fields (Table 1). For example, a data detection system has been proposed in the development of electronic health records to discover new findings, leading to efficient and safe clinical practice $[15,16]$. In the genomics and proteomics field, data mining contribute their analysis as multidimensional tests, cluster analysis and pathway analysis
C Biomed Central

(C) 2011 Takita et al; licensee BioMed Central Ltd. This is an Open Access article distributed under the terms of the Creative Commons Attribution License (http://creativecommons.org/licenses/by/2.0), which permits unrestricted use, distribution, and reproduction in any medium, provided the original work is properly cited. 
Table 1 Conceptual differences of data mining approach.

\begin{tabular}{|c|c|c|c|}
\hline Research area & Electronic medical record & Genomics/Proteomics & $\begin{array}{l}\text { This study: Mental health on } \\
\text { NDS }\end{array}$ \\
\hline Data source & $\begin{array}{l}\text { Physicians/nurses' Description, } \\
\text { laboratory data and radiologic } \\
\text { images on medical record }\end{array}$ & $\begin{array}{l}\text { Gene expression data from cDNA microarray/mass } \\
\text { spectrometry }\end{array}$ & Interview with the subject \\
\hline Expected results & $\begin{array}{l}\text { Automatic and effective data } \\
\text { extraction/sorting }\end{array}$ & $\begin{array}{l}\text { Extraction of genes/proteins with statistical significance } \\
\text { Classification of gene/proteins } \\
\text { Visualization of gene/protein expression pattern or } \\
\text { pathway }\end{array}$ & $\begin{array}{l}\text { Extraction of important and } \\
\text { rarely-appeared words } \\
\text { Visualization of relationship } \\
\text { between keywords }\end{array}$ \\
\hline Concept* & Supervised/Unsupervised approach & Supervised/Unsupervised approach & Unsupervised approach \\
\hline $\begin{array}{l}\text { Representative } \\
\text { algorism of data } \\
\text { mining technique }\end{array}$ & $\begin{array}{l}\text { Data extraction matching with } \\
\text { prepared data criteria }\end{array}$ & $\begin{array}{l}\text { To provide statistically meaningful analysis for high- } \\
\text { throughput and multi-dimensional biological data in } \\
\text { the association with phenotype }\end{array}$ & $\begin{array}{l}\text { To discover unanticipated, rarely } \\
\text { appeared key-elements by } \\
\text { Scenario Map analysis }\end{array}$ \\
\hline Aims & $\begin{array}{l}\text { Linking between medical record } \\
\text { description and research issues } \\
\text { To develop effective and } \\
\text { commonly available electronic } \\
\text { health record }\end{array}$ & $\begin{array}{l}\text { To discover new biomarker or diagnostic method } \\
\text { To discover therapeutic target }\end{array}$ & $\begin{array}{l}\text { For better clinical follow-up by } \\
\text { understanding unanticipated } \\
\text { individual concerns }\end{array}$ \\
\hline
\end{tabular}

Conceptual differences of data mining approach in representative medical research areas are shown. * Supervised approach aims for testing or validation of hypothesis while unsupervised approach used for discovering unanticipated events or knowledge.

[17-19]. The concept of data mining algorithm can be divided into two groups in the medical field; supervised and unsupervised approach [20]. The supervised approach is a traditional style of data analysis where prepared hypotheses are tested to evaluate the statistical significance, accuracy and validity. The unsupervised approach is a process to explore new knowledge called 'knowledge discovery'. Knowledge discovery is an excellent tool to generate new hypotheses effectively as shown by some reports with a text mining method on literature review and medical records [21-24]. Herein we thought that knowledge discovery would provide us unanticipated and useful keywords or relationships from clinical interviews, leading to better clinical follow-up.

The Scenario Map analysis is a new approach of knowledge discovery where the relationships among keywords in plain texts can be visualized as a diagram called KeyGraph [25,26]. The Scenario Map allows figuring out important keywords linking different conditions/ events even though they are infrequently using words, and in turn discovering new findings or knowledge through the human-computer interaction process. This process is the repeated circle between computer outputs of KeyGraph from dataset and the interpretation by humans (Figure 1). Successful studies with the Scenario maps in clinical laboratory tests and designing new products have already been reported $[27,28]$. Thus the extended study using this novel data mining approach to mental health care for NDS should be considered although few reports with the approach have been demonstrated to date. This is the first report focusing on the mental health issues of a NDS using the Scenario map.

\section{Case description}

\section{Case summary}

The subject is a 47-year-old woman. When her younger sister developed chronic myeloid leukemia, she was 27 years old and living in the United States with her husband and their two children, apart from her parents and her younger sister since her marriage. The subject shared information on the treatment of leukemia with her sister at the disease onset and learned about alloHSCT for the first time. She had a positive sense of allo-HSCT; however she did not match with her younger sister for human leucocyte antigen (HLA). Thus, she was not selected as a donor and the bone

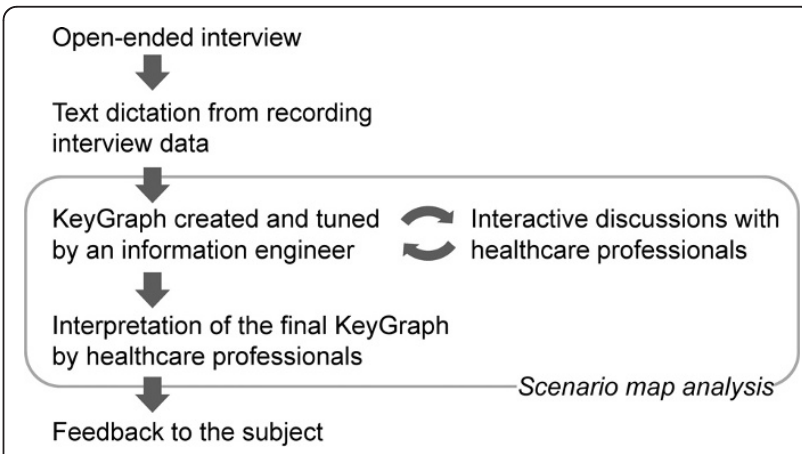

Figure 1 A working flow. The subject was interviewed using open-ended question style and text data of the interview was generated. KeyGraph was created and tuned by an information engineer in discussion with healthcare professionals. The final KeyGraph was interpreted in detail by healthcare professionals and provided the subject the feedback. Scenario Map analysis includes interactive framework between computer outputs by an information engineer and healthcare professionals to obtain a comprehensive graph. 
marrow transplantation was performed with her mother as the donor. Twenty years have passed since the transplantation and the subject's younger sister was still living at the time of this study.

The subject was interviewed by a hematologist who was not involved in the transplantation. The openended interview was carried out without prepared questions to avoid misleading results by interviewers. The subject voluntarily talked about the clinical course in her younger sister from the disease onset until the present day including her sense, feelings, family-relationships and job. The subject participated in this study voluntarily and consented to the interview being recorded and analyzed by an information engineer.

This study was approved by the Institutional Review Board of The Institute of Medical Science, The University of Tokyo (19-19-1105).

\section{Scenario Map analysis}

The recorded data was dictated to use as plain text data. The independent information engineer created a KeyGraph as previously described $[25,26]$. First, word frequency and the co-occurrence of words, meaning the coefficients on paired words in the same sentence, were determined (Table 2). Then, a well-experienced information engineer programmed settings on highly-frequent and tightly-paired words repeatedly to obtain a comprehensive KeyGraph in discussion with physicians and a nurse, since the definition of high frequency and cooccurrence can influence keyword clustering [26]. This human-computer interaction is an important step in Scenario Map Analysis allowing creative ideas in investigators. In this study, highly-frequent words were defined as words that appeared more than 6 times in the interview. The KeyGraph can visualize relationship among main structure as cluster consisted of highly-frequent and co-occurrent words (block nodes and solid lines in Figure 2) and words that appeared infrequently (white nodes). The white nodes linking between main structures are keywords, which should be focused on in this analysis.

Medical doctors and a nurse discussed relationships among clusters and keywords in the final KeyGraph and generated hypotheses on her mental health issue. The KeyGraph and hypotheses were sent via e-mail to the subject in order to validate them. Figure 1 shows a working flow of this study.

\section{Interpretation of KeyGraph}

A total of one hour and 11 minutes was taken for the interview. Based on the discussion among physicians
Table 2 The list of words in frequency and co-occurrence order.

\begin{tabular}{lll}
\hline Cluster & Word & Frequency \\
\hline Pre-transplant & Sibling & 10 \\
\hline & The most & 9 \\
\hline & Next & 8 \\
\hline & Place $D^{*}$ & 8 \\
\hline & Doctor $A^{*}$ & 7 \\
\hline & Word & 6 \\
\hline & Results & 6 \\
\hline
\end{tabular}

\begin{tabular}{lll}
\hline Emotion & Child & 126 \\
\hline & Mind & 15 \\
\hline & Person $A^{*}$ & 11 \\
\hline Suffering & 10 \\
\hline Paralysis & 7 \\
\hline Absolute & 6 \\
\hline
\end{tabular}

\begin{tabular}{lll}
\hline Transplantation process & Place $\mathrm{G}^{*}$ & 12 \\
\hline & Telephone & 10 \\
\hline & Doctor $\mathrm{B}^{*}$ & 7 \\
\hline
\end{tabular}

\begin{tabular}{lll}
\hline Subject's life & Elder sister & 16 \\
\hline & Leukemia & 9 \\
\hline Nursing & 8 \\
\hline University & 7 \\
\hline
\end{tabular}

\begin{tabular}{lll}
\hline Other** $^{*}$ & Younger sister & 50 \\
\hline & Myself & 48 \\
\hline & Bone marrow & 46 \\
\hline & Father & 44 \\
\hline Transplant & 43 \\
\hline Mother & 42 \\
\hline Previous & 24 \\
\hline Patient & 23 \\
\hline Kid & 21 \\
\hline Place A* & 21 \\
\hline Bank & 18 \\
\hline Place B* & 16 \\
\hline Donor & 15 \\
\hline Hospital & 15 \\
\hline Blastic crisis & 14 \\
\hline Mom & 12 \\
\hline Family & 10 \\
\hline HLA & 10 \\
\hline Home & 10 \\
\hline
\end{tabular}


Table 2 The list of words in frequency and co-occurrence order. (Continued)

\begin{tabular}{ll}
\hline Together & 7 \\
\hline Book & 6
\end{tabular}

Words appearing more than 6 times in the interview were defined as highfrequency in this study. Words in the same cluster have high co-occurrence each other. *Replaced words to protect personal information. **Words independently placed or had low-levels of co-occurrence with the other words in KeyGraph.

and a nurse using KeyGraph, the following four clusters were indentified: pre-transplant, emotion, transplant process, and subject's life (Figure 3). Furthermore, we extracted 'mother and child', 'announcement', 'report', 'matching', 'marriage', and 'husband' as keywords linking the clusters (Figure 3).

The emotion cluster includes frequently used words of 'suffering', 'absolute', 'paralysis', 'mind', 'Person A' and 'child'. Among them, the word 'paralysis' was used as a 'paralysis of the mind' to express a condition where the subject was unable to control her emotions because of mental stress. In addition, Person A was a younger child of NDS similar to the subject and the subject projected her feeling onto Person A in the interview. A high-frequency word of 'myself' is linked with the emotion cluster via 'body'. These findings deduced that the subject suffered emotional distress related to the treatment of her younger sister.

'Marriage', 'husband' and 'mother and child' are keywords linking clusters, suggesting that they would play an important role for the subject. Especially, 'marriage' is a keyword linking between emotion and subject's life clusters. The subject was already married when her sister developed symptoms of leukemia. In contrast, the words 'father', 'family' and 'younger sister', which should be closely related to the subject herself, were not linked with any words and clusters in the KeyGraph. Twenty years ago, it was difficult to conduct bone marrow transplantation without sibling donors since there was no bone marrow bank in Japan at that time. In this case, the subject was a NDS because of HLA mismatch. Considering these backgrounds and links in the KeyGraph together, the analysts interpreted that the subject had a feeling of isolation from her family due to being a NDS and that the subject was mentally supported by her

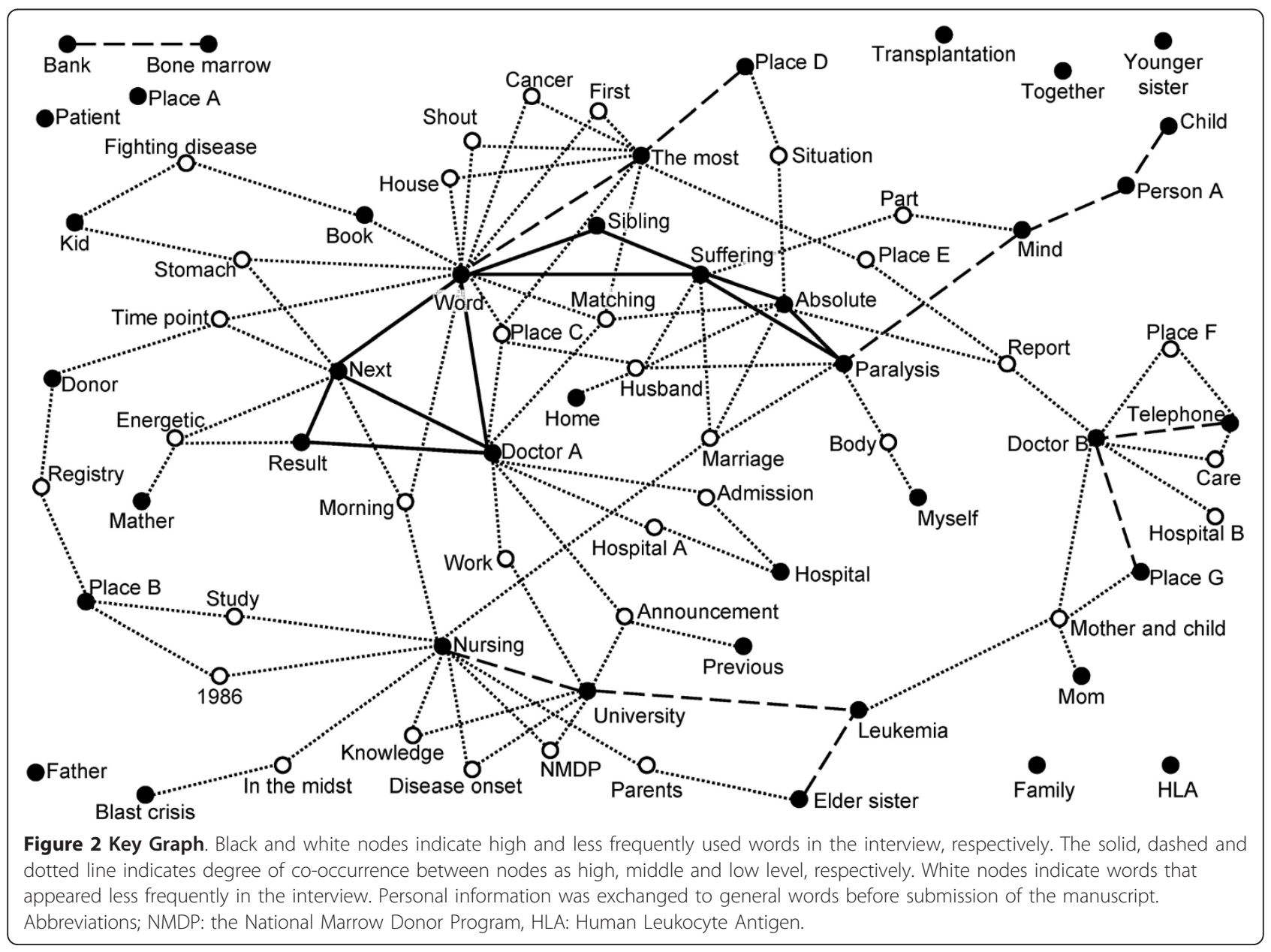




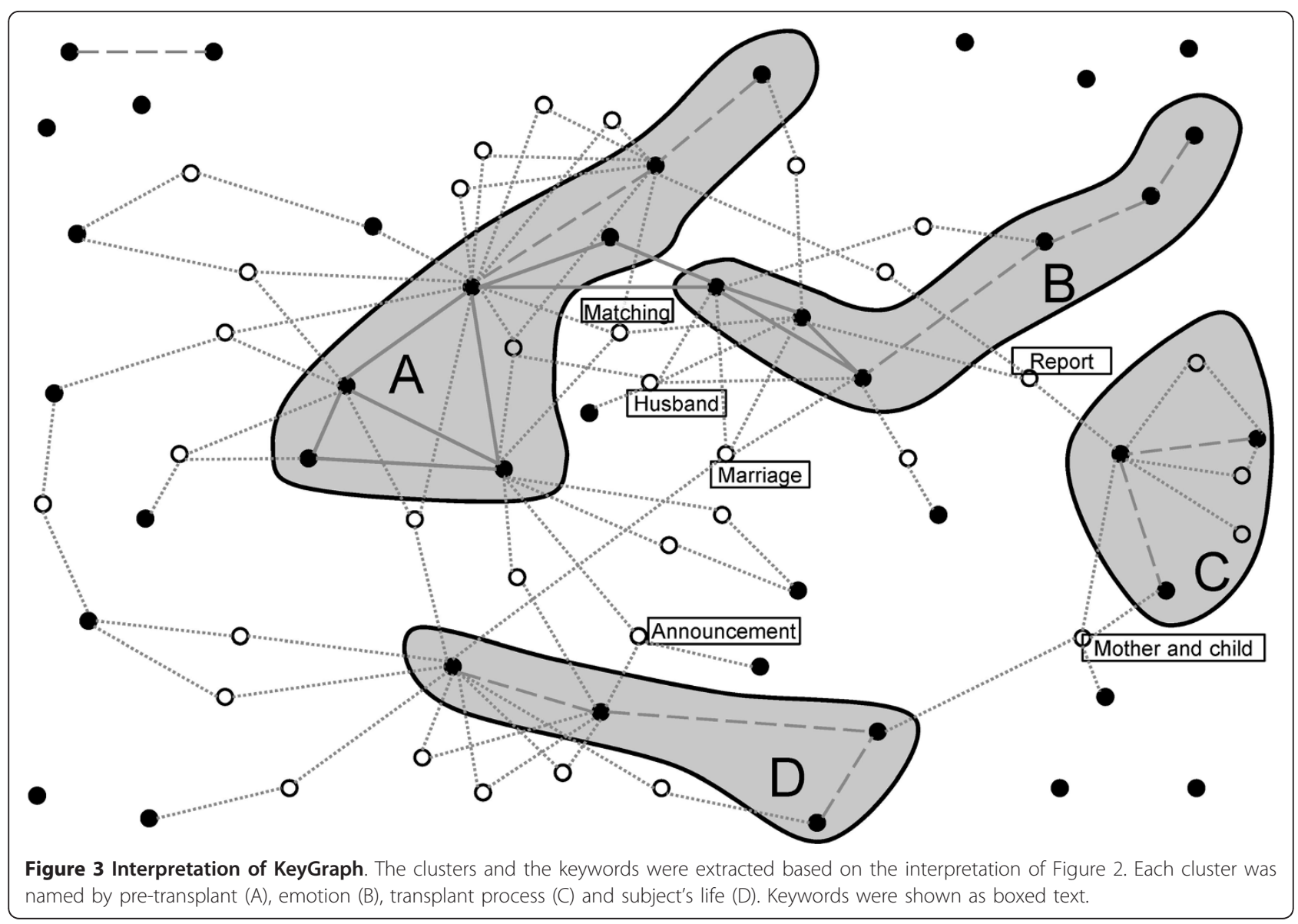

husband or mother. Of note, the links between emotion cluster, 'husband' and 'marriage' might suggest negative impact on her mind since emotion cluster represents psychological suffering.

'Report' is a keyword that connected with the transplant process and emotions cluster. Similarly, 'announcement' is linking between pre-transplant and subject's life cluster. According to our discussions, the emotional distress was related to 'report' on her sister's treatment such as the results of laboratory tests and clinical examinations and announcement of disease would have an influence on the subject's life before transplantation.

Based on the interpretations described above, we hypothesized that the subject suffered from emotional distress related to her sister's treatment and that husband and mother was a psychological mainstay for her.

The two figures were presented to the subject while our interpretations and hypothesis were not shown to her in order to avoid misleading conclusions. After reviewing the KeyGraphs, the subject said that she has had psychological stress because of the fact that she was not selected as the donor during the subsequent course of her sister's treatment and that currently she had mental health issues of being a NDS. Furthermore, when she saw the keywords 'husband' and 'married', which were linked to the emotion cluster with the others, she realized that her husband kindly supported her. This was consistent with our hypothesis obtained from discussions using the Scenario Map analysis.

\section{Discussion}

This is the first report to implement the Scenario Map analysis as a novel data mining tool into the qualitative assessment of mental health on NDSs although preliminary conclusions with caution should be regarded on this paper due to the nature of single case study. Psychological issues among patient families can be developed with bone marrow transplantation [29-31]. However, the long-term, psychological impact of the transplantation on NDS has not been well studied to date $[11,12]$. Of note, the subject in this study has had emotional distress for more than 20 years since the transplant, suggested by the interpretation of KeyGraph. This might be related to her feelings of alienation due to not being a donor. The assessment of mental health issues on NDSs using Scenario Map analysis should be 
studied with a large cohort and we are planning further studies with similar cases.

In this study, Scenario Map analysis was used for a data mining tool and enabled both clinicians and the subject to be aware of the new findings on mental health issues for NDS. It was also helpful to notice that the NDS's psychological stress can be healed by family's support through the process of the Scenario Map. Since the subject has known that she felt a psychological stress related to her younger sister's treatment, the words indicating emotional conditions appeared frequently in the interview. On the contrary, she did not mention her family's support in the interview, but recognized it after reviewing the KeyGraph. Regarding stress coping, self-recognition of familial support is beneficial to reduce her/his anxiety [32]. Medical interview with the Scenario map would improve clinical management of bone marrow transplant patients and their families including psychological problems.

Clinical relevance of the findings presented here would be helpful for patient/family support during or after allo-HSCT rather than donor selection since donor selection from family is usually performed on the basis of biological assessment of HLA matching and physical tolerability for hematopoietic stem cell harvest $[33,34]$. Previous paper showed that better scores on family support were associated with decreased risk of mortality or reduced patients' anxiety, suggesting that psycho-social care for patient family should be considered for better treatment outcome $[29,35,36]$. Therefore the approach in this case presentation suggests clinical availability in psycho-social care.

A major research method on psycho-social care for patient family is interview-based, qualitative approach and fewer quantative studies [12]. This might be explained by the difficulty to point out key issues from individual experiences of different patient/family. Text data mining is beneficial in such circumstance since data mining allows both aspects of research style; quantative approach such as frequency and co-occurrence of words and qualitative study like interpretation of the interview. This manuscript also showed a new field to bridge between mental health care and text data mining, suggesting novel collaborations between clinicians and information engineers.

There are some limitations in this approach; KeyGraph has flexibility to allow creative hypothesis generation but reproducibility of the graph is limited since the settings of high frequency and co-occurrence depend on analysts' perceptions to obtain a comprehensive graph. Therefore Scenario Map analysis should be used for discovering new hypotheses, not for validation study. Also analysts should know the background of the objectives to interpret KeyGraph effectively as analysts understood social background of all-HSCT in this study. The combination of Scenario Map analysis and subsequent traditional style of statistical study would be a more powerful tool to create new findings with liability and this study positions at the initial stage of the series.

\section{Conclusions}

This case study suggests the following points: NDSs may have a long-term emotional distress, family support is important in solving it, and the Scenario Map analysis can be useful to assess NDS's mental health issues. Thus, this case report proposed an informative method in mental health care after bone marrow transplantation although this report shows preliminary results with single case indicating limited usefulness and reliability. The methodology in this study needs to be validated in an extensive study with a large number of cases.

\section{Abbreviations}

Allo-HSCT: allogenic hematopoietic stem cell transplantation; NDS: nondonor siblings; HLA: human leukocyte antigen.

\section{Acknowledgements}

The authors thank Ana M. Rahman for English editing.

\section{Author details}

${ }^{1}$ Division of Social Communication System for Advanced Clinical Research, the Institute of Medical Science, the University of Tokyo, 4-6-1 Shirokanedai, Minato-ku, Tokyo 108-8639, Japan. ${ }^{2}$ Department of Systems Innovation, School of Engineering, the University of Tokyo, 7-3-1 Hongo, Bunkyo-ku, Tokyo 113-8656, Japan.

\section{Authors' contributions}

MT participated in the study design, interpretation of results, discussion and preparation of the manuscript. YT participated in the study design, coordination, interview, interpretation of results and discussion, and helped to prepare the manuscript. YKO participated in the study design, coordination, interpretation of results and discussion. NM participated in study design and discussion. $\mathrm{NH}$ participated in coordination and discussion. YKI participated in study design and discussion, and helped to draft the manuscript. TM participated in coordination and discussion. YO participated in information engineering and discussion. MK participated in the study design, discussion and preparation of the manuscript. All authors read and approved the final manuscript.

\section{Competing interests}

The authors declare that they have no competing interests.

Received: 8 June 2011 Accepted: 20 July 2011 Published: 20 July 2011

\section{References}

1. Copelan EA: Hematopoietic stem-cell transplantation. N Engl J Med 2006, 354:1813-1826.

2. Arellano ML, Langston A, Winton E, Flowers CR, Waller EK: Treatment of relapsed acute leukemia after allogeneic transplantation: a single center experience. Biol Blood Marrow Transplant 2007, 13:116-123.

3. Trends in the first stem cell transplants by mode. [http://www.jshct.com/ report_2009/2-8.pdf].

4. Bredeson C, Leger C, Couban S, Simpson D, Huebsch L, Walker I, Shore T, Howson-Jan K, Panzarella T, Messner H, Barnett M, Lipton J: An evaluation of the donor experience in the Canadian multicenter randomized trial of bone marrow versus peripheral blood allografting. Biol Blood Marrow Transplant 2004, 10:405-414. 
5. Fortanier C, Kuentz M, Sutton L, Milpied N, Michalet M, Macquart-Moulin G, Faucher C, Le Corroller AG, Moatti JP, Blaise D: Healthy sibling donor anxiety and pain during bone marrow or peripheral blood stem cell harvesting for allogeneic transplantation: Results of a randomised study. Bone Marrow Transplant 2002, 29:145-149.

6. Christopher KA: The experience of donating bone marrow to a relative. Oncol Nurs Forum 2000, 27:693-700.

7. Switzer GE, Myaskovsky L, Goycoolea JM, Dew MA, Confer DL, King R: Factors associated with ambivalence about bone marrow donation among newly recruited unrelated potential donors. Transplantation 2003, 75:1517-1523.

8. Packman W, Gong K, VanZutphen K, Shaffer T, Crittenden M: Psychosocial adjustment of adolescent siblings of hematopoietic stem cell transplant patients. J Pediatr Oncol Nurs 2004, 21:233-248.

9. Parmar G, Wu JW, Chan KW: Bone marrow donation in childhood: one donor's perspective. Psychooncology 2003, 12:91-94.

10. MacLeod KD, Whitsett SF, Mash EJ, Pelletier W: Pediatric sibling donors of successful and unsuccessful hematopoietic stem cell transplants (HSCT): a qualitative study of their psychosocial experience. J Pediatr Psychol 2003, 28:223-230.

11. Wilkins $K L$, Woodgate $R L$ : An interruption in family life: siblings' lived experience as they transition through the pediatric bone marrow transplant trajectory. Oncol Nurs Forum 2007, 34:e28-e35.

12. Matsubara TC, de Carvalho EC, Canini SR, Sawada NO: Family crisis in the context of bone marrow transplantation: an integrative review. Rev Lat Am Enfermagem 2007, 15:665-670.

13. Hobbs GR: Data mining and healthcare informatics. Am J Health Behav 2001, 25:285-289.

14. lavindrasana J, Cohen G, Depeursinge A, Müller H, Meyer R, Geissbuhler A: Clinical data mining: a review. Yearb Med Inform 2009, 121-133.

15. Kristianson KJ, Ljunggren H, Gustafsson LL: Data extraction from a semistructured electronic medical record system for outpatients: a model to facilitate the access and use of data for quality control and research. Health Informatics J 2009, 15:305-319.

16. Zalis $M$, Harris $M$ : Advanced search of the electronic medical record: augmenting safety and efficiency in radiology. J Am Coll Radiol 2010, 7:625-633

17. Gerling IC, Singh S, Lenchik NI, Marshall DR, Wu J: New data analysis and mining approaches identify unique proteome and transcriptome markers of susceptibility to autoimmune diabetes. Mol Cell Proteomics 2006, 5:293-305.

18. Lee JK, Williams PD, Cheon S: Data mining in genomics. Clin Lab Med 2008, 28:145-166.

19. Yang $Y$, Adelstein SJ, Kassis Al: Target discovery from data mining approaches. Drug Discov Today 2009, 14:147-154.

20. Berger AM, Berger CR: Data mining as a tool for research and knowledge development in nursing. Comput Inform Nurs 2004, 22:123-131.

21. Agarwal $P$, Searls DB: Literature mining in support of drug discovery. Brief Bioinform 2008, 9:479-492.

22. Jelier R, Schuemie MJ, Veldhoven A, Dorssers LC, Jenster G, Kors JA: Anni 2.0: a multipurpose text-mining tool for the life sciences. Genome Biol 2008, 9:R96.

23. Chen ES, Hripcsak G, Xu H, Markatou M, Friedman C: Automated acquisition of disease drug knowledge from biomedical and clinical documents: an initial study. J Am Med Inform Assoc 2008, 15:87-98.

24. Petric I, Urbancic T, Cestnik B, Macedoni-Luksic M: Literature mining method RaJoLink for uncovering relations between biomedical concepts. J Biomed Inform 2009, 42:219-227.

25. Ohsawa Y: Chance Discovery: The Current States of Art. In Chance Discoveries in Real World Decision Making Data-based Interaction of Human Intelligence and Artificial Intelligence. Edited by: Ohsawa Y, Tsumoto S. Heidelberg, Germany: Springer Berlin Heidelberg; 2006:3-20.

26. Ohsawa Y: Data crystallization: chance discovery extended for dealing with unobservable events. New Mathematics and Natural Computation 2005, 1:373-392

27. Ohsawa Y, Usui M: Creative marketing as application of chance discovery. In Chance Discovery in Real World Decision Making, Computational Intelligence. Edited by: Ohsawa Y, Tsumoto S. Heidelberg, Germany: Springer Berlin Heidelberg; 2006:253-272.

28. Ohsawa Y: Scenario maps on situational switch model, applied to bloodtest data from hepatitis c patients. In Chance Discovery in Real World
Decision Making, Computational Intelligence. Edited by: Ohsawa Y, Tsumoto S. Heidelberg, Germany: Springer Berlin Heidelberg; 2006:69-80.

29. Lynna L: Bone marrow transplantation: support of the patient and his/ her family. Support Care Cancer 1994, 2:35-49.

30. Bishop MM, Beaumont JL, Hahn EA, Cella D, Andrykowski MA, Brady MJ, Horowitz MM, Sobocinski KA, Rizzo JD, Wingard JR: Late effects of cancer and hematopoietic stem-cell transplantation on spouses or partners compared with survivors and survivor-matched controls. J Clin Oncol 2007, 25:1403-1411.

31. Fife BL, Monahan PO, Abonour R, Wood LL, Stump TE: Adaptation of family caregivers during the acute phase of adult BMT. Bone Marrow Transplant 2009, 43:959-966.

32. Folkman S: The case for positive emotions in the stress process. Anxiety Stress Coping 2008, 21:3-14.

33. Pamphilon D, Siddiq S, Brunskill S, Dorée C, Hyde C, Horowitz M, Stanworth S: Stem cell donation: what advice can be given to the donor? Br J Haematol 2009, 147:71-76.

34. Oudshoorn M, van Walraven SM, Bakker JN, Lie JL, V D Zanden HG, Heemskerk MB, Claas FH: Hematopoietic stem cell donor selection: the Europdonor experience. Hum Immunol 2006, 67:405-412.

35. Foster LW, McLellan L, Rybicki L, Dabney J, Visnosky M, Bolwell B: Utility of the psychosocial assessment of candidates for transplantation (PACT) scale in allogeneic BMT. Bone Marrow Transplant 2009, 44:375-380.

36. Schulz-Kindermann F, Hennings U, Ramm G, Zander AR, Hasenbring M: The role of biomedical and psychosocial factors for the prediction of pain and distress in patients undergoing high-dose therapy and BMT/PBSCT. Bone Marrow Transplant 2002, 29:341-351.

doi:10.1186/2043-9113-1-19

Cite this article as: Takita et al:: Data mining of mental health issues of non-bone marrow donor siblings. Journal of Clinical Bioinformatics 2011 1:19.

\section{Submit your next manuscript to BioMed Central and take full advantage of:}

- Convenient online submission

- Thorough peer review

- No space constraints or color figure charges

- Immediate publication on acceptance

- Inclusion in PubMed, CAS, Scopus and Google Scholar

- Research which is freely available for redistribution

Submit your manuscript at www.biomedcentral.com/submit
C) Biomed Central 